\title{
Hypertrophic Osteoarthropathy and Digital clubbing in Lung Adenocarcinoma
}

\author{
By Konstantinos Michalakis, $\mathrm{MD}^{1 \otimes}$ Dimitrios-Anestis Moutzouris, $\mathbf{M D}^{2}$
}

The Foot and Ankle Online Journal 2 (7): 2

Hypertrophic osteoarthropathy (HOA) is characterized by digital clubbing, tubular bones periostosis and synovial effusions mostly in the large joints. While HOA can present as primary bone disease, it is often encountered in lung adenocarcinoma. Although not directly relevant to foot diseases, we believe that the characteristics of hypertrophic osteoarthropathy should be recognized among podiatrists and in general physicians involved with hand and foot abnormalities. We believe that the submitted clinical image has educational value for medical students, residents, and practicing clinicians. The physician should recognize digital clubbing when evaluating a patient with such a clinical manifestation, shortening the time to diagnosis and improving the outcome. A case report and discussion is presented describing HOA features.

Key Words: Hypertrophic Osteoarthropathy, digital clubbing

Accepted: June, 2009

Published: July, 2009

This is an Open Access article distributed under the terms of the Creative Commons Attribution License. It permits unrestricted use, distribution, and reproduction in any medium, provided the original work is properly cited. (The Foot and Ankle Online Journal (www.faoj.org)

$\mathrm{H}$ ypertrophic osteoarthropathy or HOA is characterized by digital clubbing, tubular bones periostosis and synovial effusions mostly in the large joints. It can be primary or secondary usually associated with lung cancer and more often with adenocarcinoma. ${ }^{1}$

\section{Case Report}

A 62 year-old man presented reporting cough, weight loss and anorexia during the last 6 months. He stated also that his fingers "look different". Medical history was remarkable for heavy smoking over 30 years. He was diagnosed with lung adenocarcinoma and HOA. (Fig. 1)

\footnotetext{
Address correspondence to: Konstantinos Michalakis ,Corresponding Author, National Institutes of Health (NIH),

Maryland, Bethesda, USA kostismichalakis@hotmail.com

Tel. +1-3477550420

Fax +30-210-6437781

${ }^{1}$ National Institutes of Health, Endocrine Dept, Bethesda, Maryland, USA.

2 Evagelismos General Hospital, Nephrology Clinic, Athens, Greece.
}

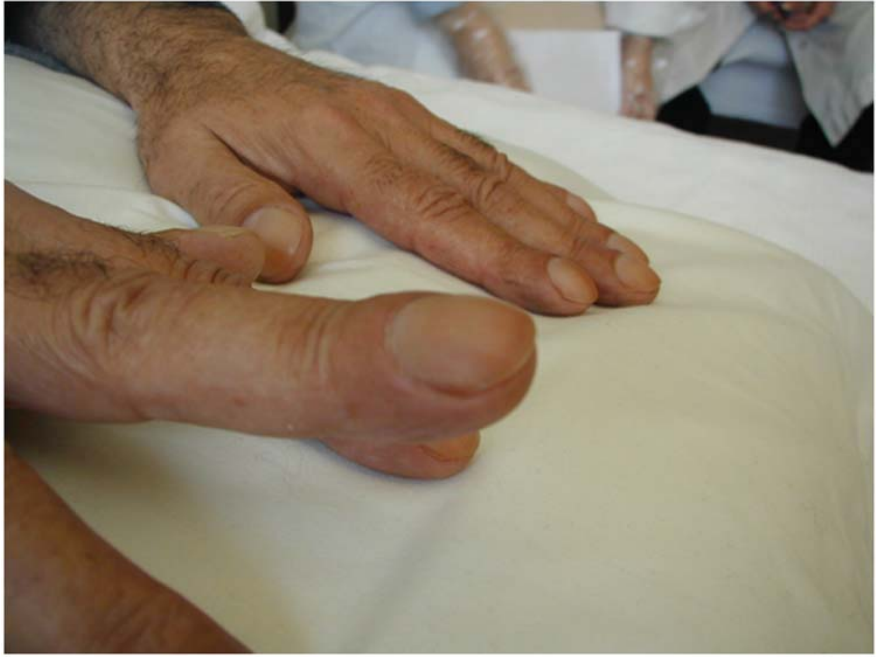

Figure 1 A 62 year-old male with diagnosed lung adenocarcinoma and associated finger nail clubbing. 


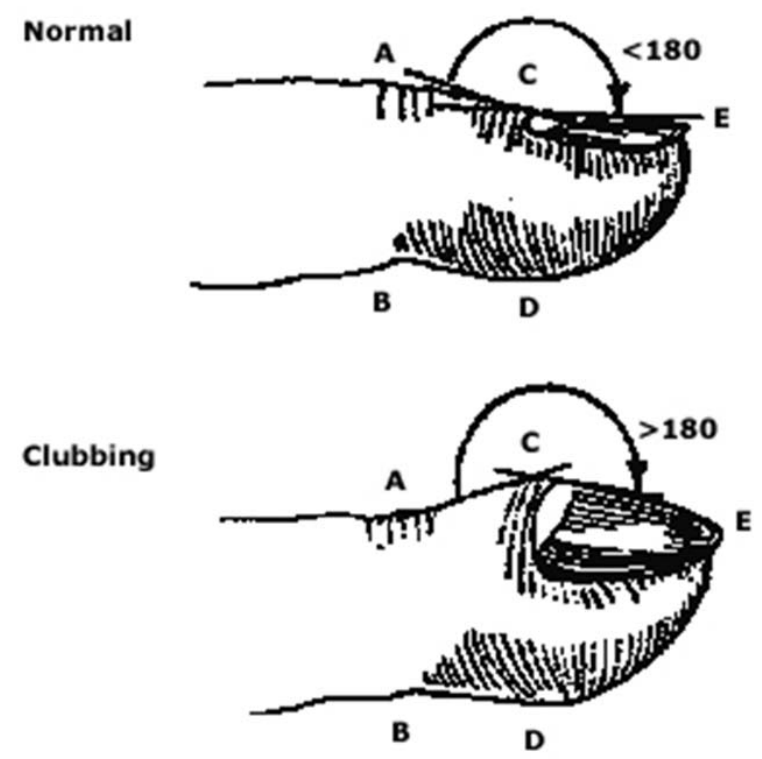

Figure 2 In the normal finger, the length of the perpendicular dropped from point A to point B should be greater than a similar line from $C$ to $D$. In clubbing, the relationships are reversed - that is, the angle between $C$ and $D$ is greater than the angle of $A$ and $B$. The other important change is the angle described by $A, C$ and $E$. In the normal finger this is usually $<180$ degrees whereas in clubbing it is $>180$ degrees. Redrawn from DeRemee, RA. Facets of the algorithmic synthesis. In: DeRemee, RA, (Ed), Clinical profiles of diffuse interstitial pulmonary disease, Mount Kisco, NY, Futura Publishing Company, Inc, 1990, pp. 9-44. (Copy with permission)

Figure 2 describes and illustrates digital clubbing. In the normal nail, the distance between $A$ and $B$ is greater than the distance between $\mathrm{C}$ and $\mathrm{D}$. This nail characteristic is reversed in clubbing. In addition, the angle described by A-C-E is characteristically $>180^{\circ}$ in clubbing, whereas in normal subjects is $<180^{\circ}$. HOA diagnosis should prompt further evaluation, since frequent causes include lung neoplasm, either primary or secondary.

\section{Discussion}

HOA is a syndrome characterized by abnormal proliferation of the skin and osseous tissue at the distal parts of the extremities. There is a primary form, not associated with any other medical disorders, and a secondary form usually associated with lung cancer, pulmonary infections, right-to-left cardiac shunts, as well as other less common entities. ${ }^{2}$

Among patients with lung cancer, HOA is most frequently associated with adenocarcinoma and least frequently with small cell carcinoma. In one series of 111 consecutive patients with pathologically proven lung cancer, clubbing was present in 29 percent; the phenomenon was more common among women than men (40 versus 19 percent).

Clinical features of HOA include digital clubbing, periostosis of tubular bones, and synovial effusions, which are most prominent in the large joints. Periostosis is usually accompanied by pain on palpation of the involved area. Some patients present with a painful arthropathy in advance of clubbing which may be confused with inflammatory arthritis.

Clubbing and HOA appear to be different manifestations of the same disease process. ${ }^{5}$ It is thought that localized activation of the plateletendothelial cells, with the subsequent release of fibroblast growth factor (s) (e.g., platelet-derived growth factor) plays an important role in the pathogenesis of HOA. ${ }^{4}$ The frequent association with lung disease raises the possibility that circulatory bypass of the lung may play an important role. One hypothesis is that megakaryocytes escape the normal fragmentation in the lung to platelets, and reach the distal extremities where they release growth factors. ${ }^{7}$

An alternate explanation involves tumor production and release into the circulation of a factor that promotes features of HOA such as vascular proliferation, edema formation, and new bone formation. One candidate is vascular endothelial growth factor (VEGF). ${ }^{8}$ 
Two case reports have independently noted elevated circulating concentrations of VEGF associated with lung cancer and evidence of tumor production of VEG. In one case, a marked decline in VEGF followed resection of tumor and was temporally correlated with clinical improvement. ${ }^{7}$

When HOA is suspected, attention should be paid to the chest because the most frequent cause of acute onset of HOA is a lung neoplasm, either primary or secondary. A bone scan is a sensitive way to detect which bones are involved. Removal of lung cancer or treatment of the other causes of HOA results in regression in the clinical manifestations. ${ }^{1}$

Rarely, arterial vascular prosthesis infections may be associated with HOA. ${ }^{3}$ Clinical features suggestive of vascular infection-related $\mathrm{HOA}$ include clubbing or periosteal new bone formation in a single limb (in the case of upper extremity arterial prostheses), or unilateral or bilateral lower extremity involvement in the case of arterial grafts to the legs or aortic prostheses.

\section{References}

1. Sridar KS, Lobo CF, Altman RD: Digital clubbing and lung cancer. Chest 114 (6): 1535 - 1537, 1998.

2. Martinez-Lavin M, Pineda C: Hypertrophic osteoarthropathy, In: Rheumatology, Hochberg MC, Silman AJ, Smolen JS et al. (Eds), Mosby, London 2003. p.1763, 2003.

3. Alonso-Bartolome P, Martinez-Taboada VM, Pina T, Blanco $\mathrm{R}$, Rodriguez-Valverde V: Hypertrophic osteoarthropathy secondary to vascular prosthesis infection: report of 3 cases and review of the literature. Medicine (Baltimore). 85:183 - 914, 2006.

4. Dickinson CJ: The aetiology of clubbing and hypertrophic Osteoarthropathy. Eur J Clin Invest 23(6): 330 - 338, 1993. 5.Martinez-Lavin M: Digital clubbing and hypertrophic osteoarthropathy: a unifying hypothesis. J Rheumatol 14 (1): 6 8, 1987.

6. Sridhar KS, Lobo CF, Altman RD. Digital clubbing and lung cancer. Chest;114(6):1535-7, 1998

7. Abe Y, Kurita S, Ohkubo Y, Usui H, Hashizume T, Nakamura M, Ueyama Y, Fujino T: A case of pulmonary adenocarcinoma associated with hypertrophic osteoarthropathy due to vascular endothelial growth factor. Anticancer Res. 22 (6B): $3485-3488,2002$.

8. Olan F, Portela M, Navarro C, Gaxiola M, Silveira LH, Ruiz V, Martinez-Lavin M: Circulating vascular endothelial growth factor concentrations in a case of pulmonary hypertrophic osteoarthropathy. Correlation with disease activity. J Rheumatol. 31(3):614-616, 2004. 